\title{
Reconfigurable Antenna using Micromechanical Actuation Switches for K and Ku-Band Applications
}

\author{
Sathuluri Mallikharjuna Rao, G. Sasikala
}

\begin{abstract}
In this paper, we have proposed a reconfigurable antenna using micro mechanical actuation switches for $K$ and Ku-band applications. Overall two identical cantilever micro mechanical switches $\left(S_{1} \& S_{2}\right)$ are used to design reconfigurable patch antenna. The switches are working by electrostatic actuation mechanism. With the switches, overall the antenna is offering four resonant frequencies based on the switches ON/OFF condition. The Micro mechanical switches are offering an isolation loss of $-18.5 \mathrm{~dB}$ and an insertion loss of $-1 \mathrm{~dB}$. The switch requires a DC actuation voltages of $6 \mathrm{~V}$. The Proposed reconfigurable antenna is resonating at four different frequencies based on the different switching conditions of $R F$ MEMS switches. If $S_{1} \& S_{2}$ both are $O N$ the antenna is resonating at $16.9 \mathrm{GHZ}$, if $S_{1}-O N \& S_{2}-O F F$ the antenna is resonating at $47.3 \mathrm{GHZ} \& 59.1 \mathrm{GHZ}$, if $S_{1}-\mathrm{OFF} \& S_{2}-\mathrm{ON}$ the antenna is resonating at $28.4 G H Z$, if $S_{1}-O F F \& S_{2}-O F F$ the antenna is resonating at $27.9 \mathrm{GHZ}$
\end{abstract}

Index Terms- Patch antenna, re-configurability, RF MEMS switch, PIN diode, FET, Polarization, bandwidth, gain, directivity.

\section{INTRODUCTION}

The latest communication applications require high speed data transmission with low power consumption, this is the significant research problem. Massive MIMO like systems require array of antennas but it eventually suffers with signal interference problems. To overcome these type of problems, we can use reconfigurable microstrip patch antennas other than the array of antennas. The re-configurability in patch antennas can be achieved with structure like E-shape, but the efficiency is not up to the level, so this approach is not preferable[1-4]. The alternative method to get reconfigurability in microstrip patch antenna is by placing switches like PiN diodes or FET transistors and RF MEMS switches. In this RF MEMS switches offering best performance compared with PiN diode and FET transistors in terms of power consumption and offers better linearity [59]. Achieving the high isolation, low insertion and low pullin voltage are the significant research challenges in micromechanical switches.

\section{Revised Manuscript Received on December 30, 2019.}

* Correspondence Author

Sathuluri Mallikharjuna Rao, Assitant Professor, Department of ECE, Andhra Loyola Institute of Engineering and Technology (Andhra Pradesh) India. E-mail: smr.aliet@gmail.com

Dr. G. Sasikala, Associate Professor, Department of ECE, Vel Tech University, Avadi, Chennai-600062 (Tamilnadu) India.

E-mail: gsasikala@veltech.edu.in

(C) The Authors. Published by Blue Eyes Intelligence Engineering and Sciences Publication (BEIESP). This is an open access article under the CC BY-NC-ND license (http://creativecommons.org/licenses/by-nc-nd/4.0/)
In this paper, we have designed and verified the performance of reconfigurable antenna using capacitive RF MEMS switches. The antenna is preferable in $\mathrm{k}$-band and ka-band applications. The eventual reconfigurable microstrip antenna design is done in three steps, as an initial task we have designed an RF MEMS switch suitable in Kband and Ku-band frequency range, in the second level a microstrip patch antenna is designed and which is suitable to place RF MEMS switches, and in the final step the RF MEMS switches are placed in the proposed microstrip antenna structure as shown in figure 9.

\section{MICROMECHANICAL SWITCH}

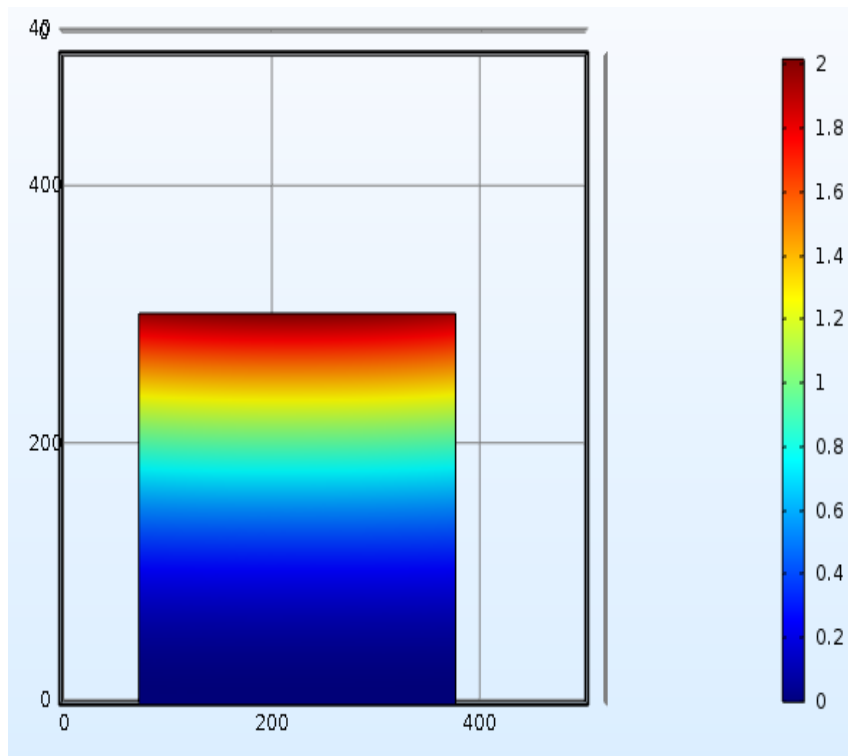

Figure 1: Micromechanical Cantilever shunt capacitve switch electromechanical analysis

The reconfigurable micro strip patch antenna design involves placing of two identical RF MEMS switches. An electrostatic shunt capacitive RF MEMS switches are used. CPW transmission line is used for switch design with dimension $100 \mu \mathrm{m}$ x100 $\mu \mathrm{m}$ x100 $\mu \mathrm{m}$.

The working principle of micro mechanical switch is, when the structure is in upstate(OFF), the input radio frequency signal is allowed to the output port with low insertion losses, and if the structure is in downstate(ON) the switch offers a capacitance in the range of $\mathrm{pF}$ and the input radio frequency signal is completely isolates and the output is zero. The electrostatic actuation model cantilever based shunt capacitive RF MEMS switch is shown in figure 1. 
Table 1: RF MEMS switch materials and dimensions

\begin{tabular}{|c|c|c|}
\hline Parameter & Material & $\begin{array}{c}\text { Dimension in } \mu m \\
\text { (Length } \mathbf{x} \text { width } \text { x thickness) }\end{array}$ \\
\hline Substrate & Silicon & $500 \times 500 \times 1600$ \\
\hline $\mathrm{CPW}$ & Gold & $100 \times 100 \times 100$ \\
\hline Cantilever & Gold & $300 \times 300 \times 1$ \\
\hline Dielectric & Silicon Nitrite $\left(\varepsilon_{\mathrm{r}}=7\right)$ & $320 \times 120 \times 0.5$ \\
\hline
\end{tabular}

Silicon is used as a substrate for RF MEMS switch, CPW lines, cantilever is designed using gold material and silicon nitride (Si3N4) is used as a dielectric material. The shunt capacitive switch is actuated with electrostatic actuation.

The switch is designed and simulated using FEM tools. The cantilever with dimensions $300 \mu \mathrm{m} \times 300 \mu \mathrm{m} \times 1 \mu \mathrm{m}$ requires an actuation voltage of $6 \mathrm{~V}$ to displace $2 \mu \mathrm{m}$ as shown in figure 1 , is the simulation result.

The pull-in voltage of the cantilever based shunt capacitive RF MEMS switch can be calculate using following mathematical equation[10-12],

$$
\text { Pull-in Voltage }=\sqrt{\frac{8 \mathrm{~kg}_{0}^{3}}{27 A \varepsilon_{0}}}
$$

where, $\mathrm{k}$ is the cantilever spring constant, $\mathrm{g} 0$ is the switch air gap, $\mathrm{A}$ is the electrodes cross sectional area, and $\varepsilon 0=8.85 \times 10-12$ is the free space relative permittivity.

The spring constant $(\mathrm{k}=(\mathrm{Ewt} 3) / \mathrm{l} 3)$ of gold cantilever structure with 300umx300umx1um dimension, $\mathrm{E}=70 \mathrm{GPa}$, is theoretically value is $0.77 \mathrm{~N} / \mathrm{m}$, the required pull-in voltage for air gap of $2 \mathrm{um}$ with actuation electrodes cross sectional area 300umx300um is $4.5 \mathrm{~V}$.

The error in the pull-in voltage result is very low that is \% of error= $=(($ Simulation-Theoretical $) /$ Theoretical $) X 100$, the error in the pull-in voltage in terms of simulation $(6 \mathrm{~V})$ and theoretical $(4.5 \mathrm{~V})$ is approximately $0.33 \%$. It is indicating that simulated one is very close to theoretical result.

The switch Radio frequency behavior is analyzed using HFSS tool. The switch overall performance is simulated in the frequency range $1 \mathrm{GHZ}$ to $60 \mathrm{GHZ}$. The insertion losses of the switch is $-1 \mathrm{~dB}$ and the isolation losses of the switch is $-18.5 \mathrm{~dB}$ as shown in figure 3 and 4 respectively.

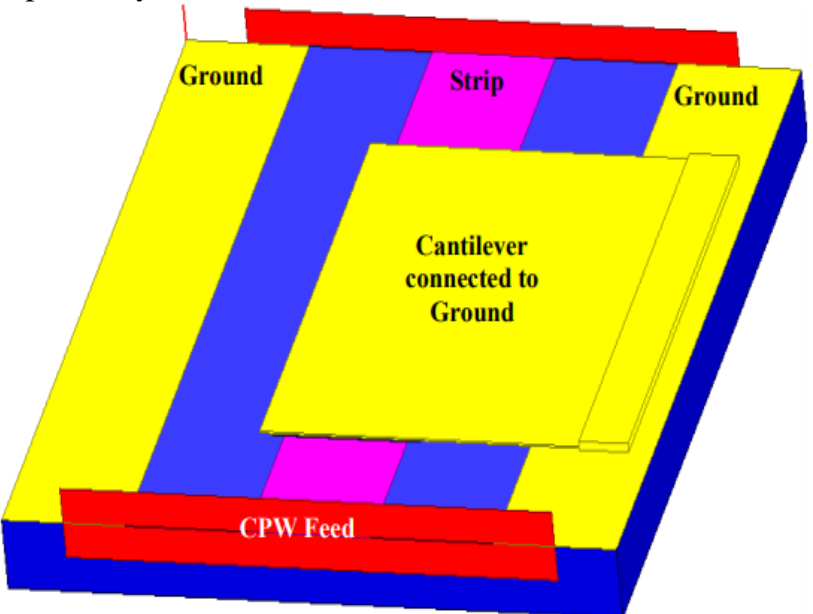

Figure 2: Micromechanical cantilever shunt capacitve switch Radio Frequency analysis.

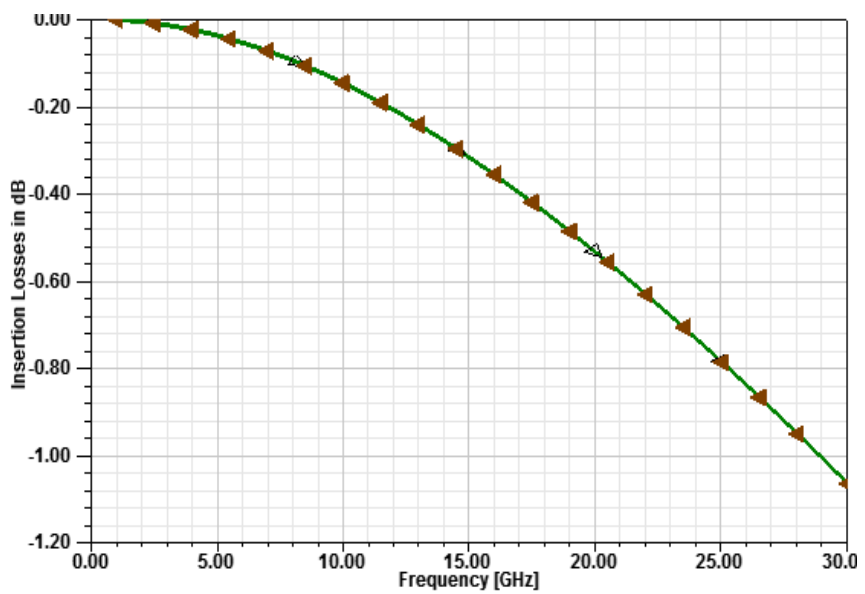

Figure 3: Insertion Losses in $\mathrm{dB}$

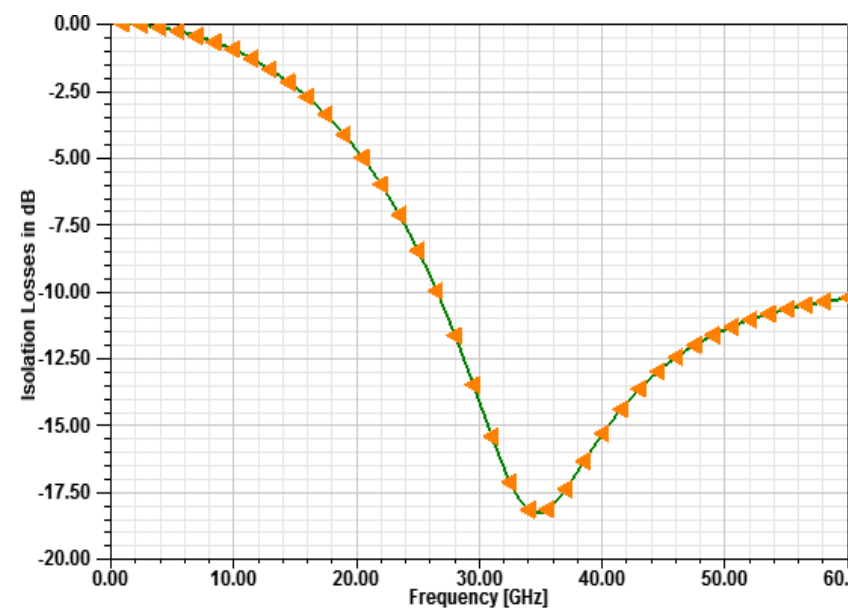

Figure 4: Isolation Losses Losses in $\mathrm{dB}$

\section{MICROSTRIP PATCH ANTENNA}

In this paper we have proposed a rectangular slotted microstrip patch antenna suitable to incorporate the RF MEMS switches as shown in figure 5. CPW feeding is used to feed microstrip antenna with input impedance of $50 \Omega$.

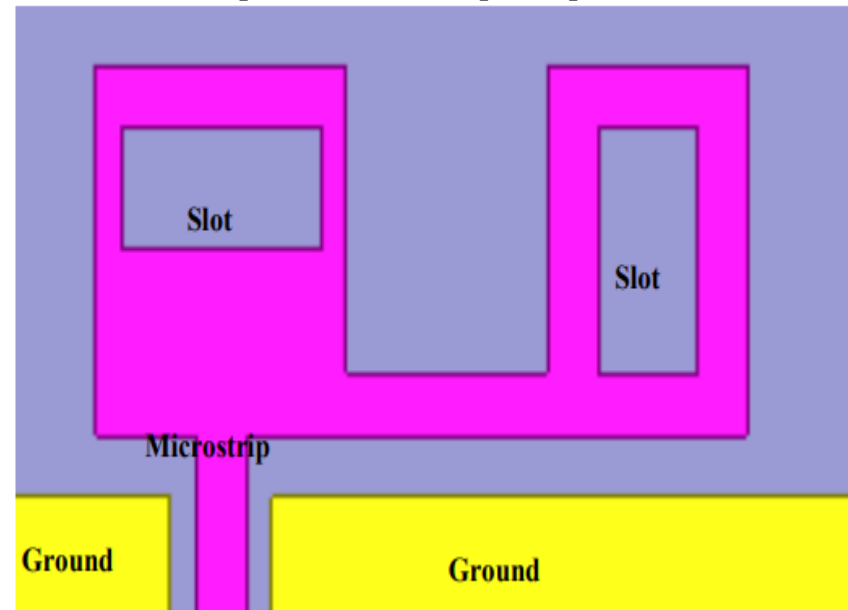

Figure 5: Proposed micro strip patch antenna suitable to incarporate RF MEMS swithes

The operating frequency of reconfigurable antenna is to be aimed in the range k-band and $\mathrm{Ku}$-band, so the basic antenna is also designed in appropriately same band.

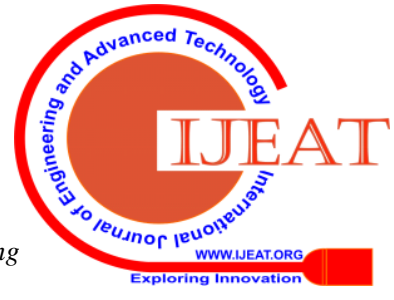




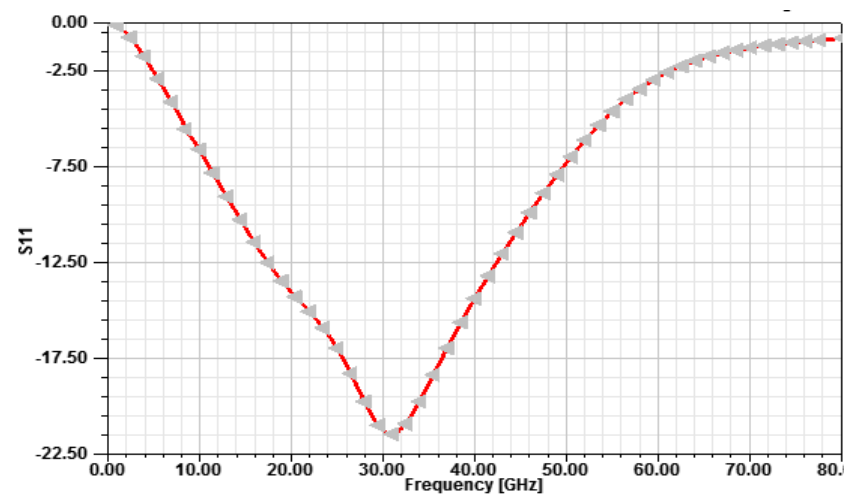

Figure 6: Micromechanical switche in microstrip patch antenna

The antenna without RF MEMS switches is resonating at 30GHZ as shown in figure 6. Here, we have extended out analysis on the performance of antenna with different substrate materials like FR4, Rogers RO3006, Glass and silicon. In this analysis we noticed that as silicon as the substrate antenna is offering best performance.

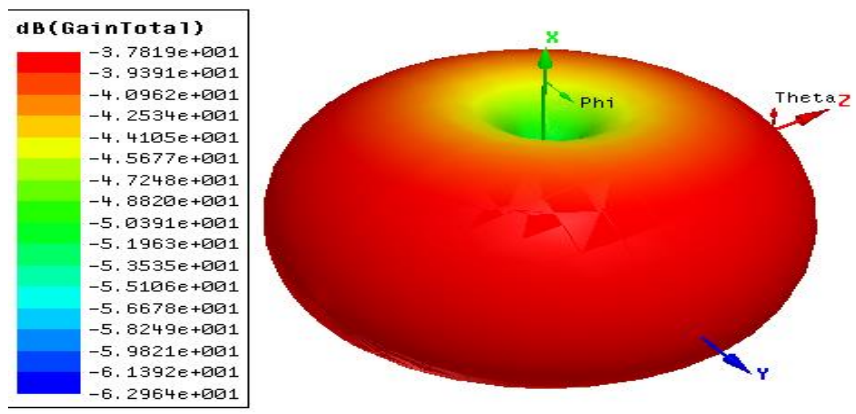

Figure 7: Polar plot of antenna with out RF MEMS switches.

The eventual reconfigurable microstrip antenna using RF MEMS switches design is discussed in this section. Overall two RF MEMS switches are placed in the proposed microstrip antenna structure which is convenient to place RF MEMS switches. Silicon with $1.6 \mathrm{~mm}$ thickness is used as a substrate material, microstrip, ground and RF MEMS switches design is done using gold material.

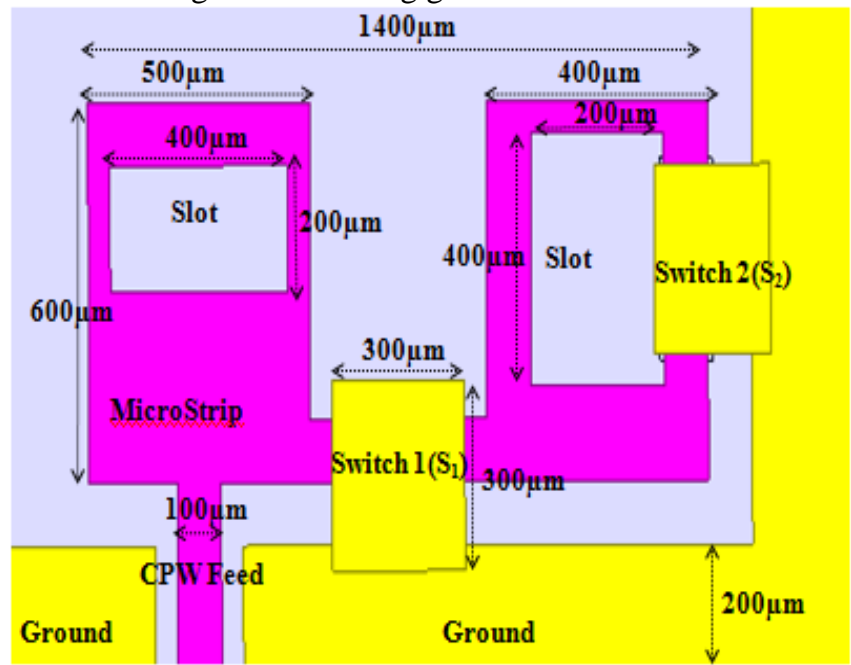

Figure 8: Proposed reconfigurable antenna model-top view

\section{PROPOSED RECONFIGURABLE ANTENNA}

Under different switching condition of RF MEMS switches the antenna resonating in different frequencies. Overall proposed reconfigurable antenna is resonating at four different frequencies.

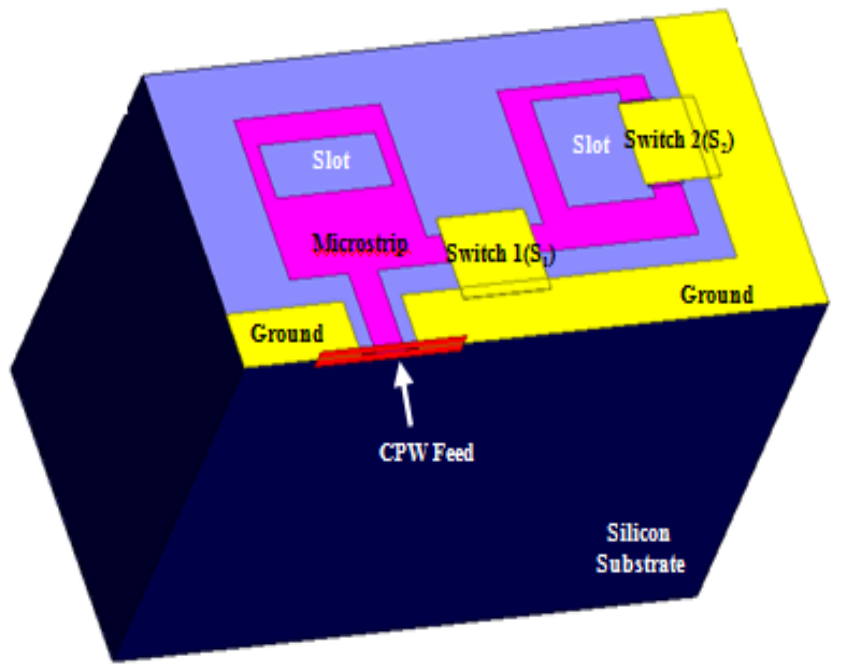

Figure 9: Proposed reconfigurable antenna model- side view

If $\mathrm{S} 1$ \& $\mathrm{S} 2$ both are $\mathrm{ON}$ the antenna is resonating at 16.9GHZ, if S1 -ON \& S2-OFF the antenna is resonating at 47.3GHZ \& 59.1GHZ, if S1 -OFF \& S2-ON the antenna is resonating at 28.4GHZ, if S1 -OFF \& S2-OFF the antenna is resonating at $27.9 \mathrm{GHZ}$.

The antenna performance is analyzed over the frequency range $1 \mathrm{GHZ}$ to $80 \mathrm{GHZ}$ using HFSS FEM tool. After observing the frequency response of the reconfigurable antenna we would like to refere the antenna in a wide range of applications in K-band and ka-band range. Other than polarization proposed antenna is switching the operating frequency from one frequency to other frequency.

Table 2: Antenna Resonant Frequencies for different switch conditions

\begin{tabular}{|c|c|}
\hline Condition & Resonant Frequency \\
\hline $\mathrm{S}_{1}=O N, \mathrm{~S}_{2}=O N$ & $16.9 \mathrm{GHZ}$ \\
\hline $\mathrm{S}_{1}=O N, \mathrm{~S}_{2}=O F F$ & $47.3 \mathrm{GHZ} \& 59.1 \mathrm{GHZ}$ \\
\hline $\mathrm{S}_{1}=O F F, \mathrm{~S}_{2}=O N$ & $28.4 \mathrm{GHZ}$ \\
\hline $\mathrm{S}_{1}=O F F, \mathrm{~S}_{2}=O F F$ & $27.9 \mathrm{GHZ}$ \\
\hline
\end{tabular}

Published By: 
Reconfigurable Antenna using Micromechanical Actuation Switches for K and Ku-Band Applications

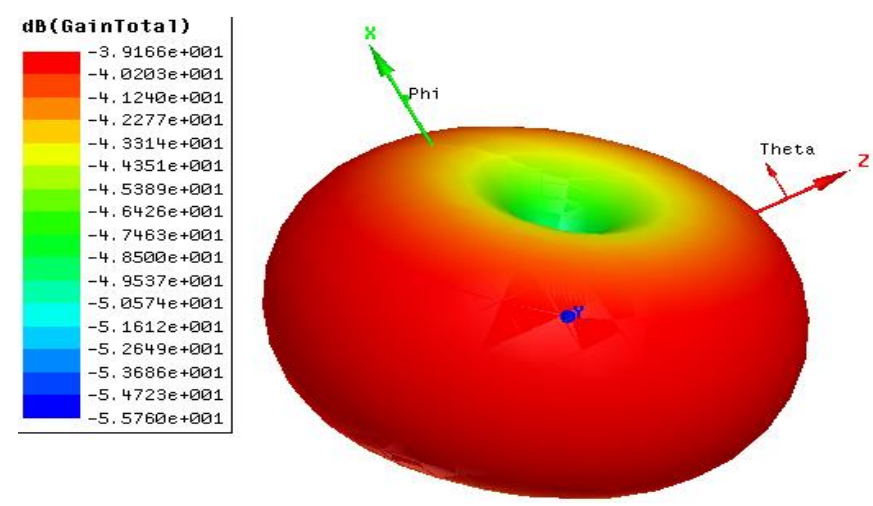

Figure 10: Polar plot of reconfigurable antenna at $S_{1}-O N \& S_{2}-O N$

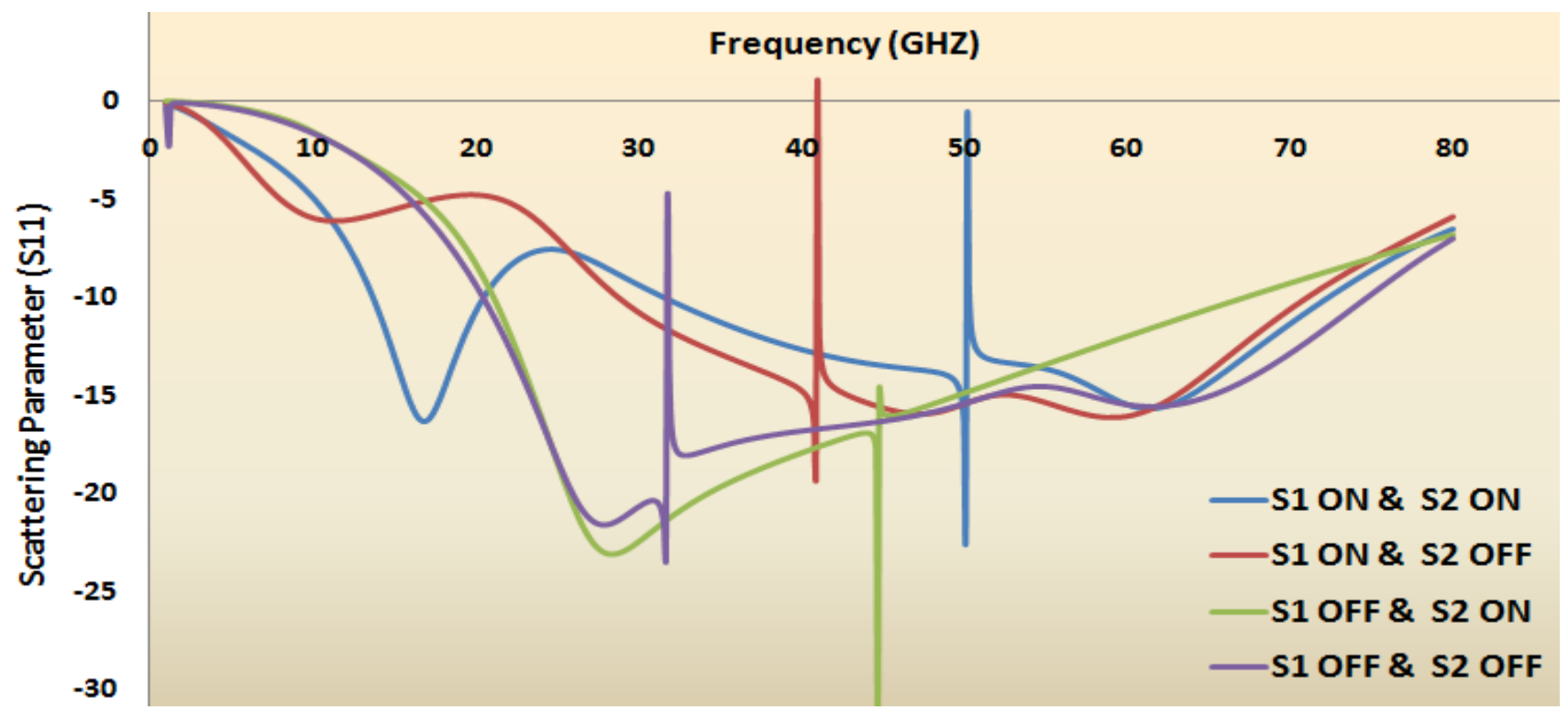

Figure 10: Scattering parameters for different switch states

Table 3:Comparison of the related work with the proposed reconfigurable antenna

\begin{tabular}{|c|c|c|c|c|c|}
\hline Survey Paper & Antenna Shape & $\begin{array}{l}\text { Number of } \\
\text { switches }\end{array}$ & Switches & Switches State and Resonant Frequency & $\begin{array}{l}\text { Antenna } \\
\text { Application }\end{array}$ \\
\hline $\begin{array}{c}\text { Harish } \\
\text { Rajagopalan et } \\
\text { al. [13] }\end{array}$ & E-shape & 2 & $\begin{array}{c}\text { RMSW100HP - SPST, } \\
\text { High Power (10 W), } \\
\text { DC-12 GHz }\end{array}$ & $\begin{array}{l}\text { S1 \& S2 : ON-2-2.6 GHz, } \\
\text { S1 \& S2 : OFF-2.6-3.2 GHz. }\end{array}$ & $\begin{array}{l}\text { Cognitive } \\
\text { Radio }\end{array}$ \\
\hline $\begin{array}{l}\text { Tony J. Jung et } \\
\text { al. [14] }\end{array}$ & Circle & 1 & DC contact RF MEMS & $\begin{array}{l}\text { S1 :OFF- Circular polarization(17.4 -21.9 GHz), } \\
\text { S1 :ON- Linear polarization(16.9-22.5 GHz). }\end{array}$ & Satellite \\
\hline $\begin{array}{l}\text { Caner Guclu et } \\
\text { al.[15] }\end{array}$ & Split rings & 6 & $\begin{array}{l}\text { Series DC contact RF } \\
\text { MEMS switch. }\end{array}$ & 24.4 GHz and 35.5 GHz independently. & $\begin{array}{l}\text { K-Band \& } \\
\text { Ka-Band. }\end{array}$ \\
\hline $\begin{array}{c}\text { Chih-Chieh } \\
\text { Cheng et al. } \\
\text { [16] }\end{array}$ & $\begin{array}{l}\text { Programmable } \\
\text { Lens-Array } \\
\text { Antenna }\end{array}$ & 5 & $\begin{array}{l}\text { Capacitive RF MEMS } \\
\text { switches. }\end{array}$ & $35 \mathrm{GHz}$ & Ka-Band \\
\hline
\end{tabular}




\begin{tabular}{|c|c|c|c|c|c|}
\hline Proposed & Slotted Rectangular & 2 & $\begin{array}{c}\text { Shunt capacitive } \\
\text { cantilever RF MEMS } \\
\text { switches }\end{array}$ & $\begin{array}{c}\mathrm{S}_{1}=\mathrm{ON}, \mathrm{S}_{2}=\mathrm{ON}: 16.9 \mathrm{GHZ} \\
\mathrm{S}_{1}=\mathrm{ON}, \mathrm{S}_{2}=\mathrm{OFF}: 47.3 \mathrm{GHZ} \& 59.1 \mathrm{GHZ} \\
\mathrm{S}_{1}=\mathrm{OFF}, \mathrm{S}_{2}=\mathrm{ON}: 28.4 \mathrm{GHZ} \\
\mathrm{S}_{1}=\text { OFF, } \mathrm{S}_{2}=\text { OFF:27.9GHX }\end{array}$ & $\begin{array}{c}\text { K-Band \& } \\
\text { Ku-Band }\end{array}$ \\
\hline
\end{tabular}

\section{CONCLUSION}

The reconfigurable microstrip antenna design is done in three steps, as an initial task we have designed an RF MEMS switch suitable in K-band and Ku-band frequency range, in the second level a microstrip patch antenna is designed and which is suitable to place RF MEMS switches, and in the final step the RF MEMS switches are placed in the proposed microstrip antenna structure. The RF MEMS capacitive shunt switch is designed with cantilever structure with electrostatic actuation. The switch requires $6 \mathrm{v}$ actuation voltage and it offers $1 \mathrm{~dB}$ insertion and $18.5 \mathrm{~dB}$ isolation. The microstrip patch antenna suitable to place RF MEMS switches is resonate at 30GHZ frequency before placing RF MEMS switches. Overall two RF MEMS switches are place in the slotted rectangular patch antenna. Under different switching condition of RF MEMS switches the antenna resonating in different frequencies. Overall proposed reconfigurable antenna is resonating at four different frequencies.

\section{ACKNOWLEDGMENT}

We would like to thank Department of ECE, K L University, AP, India, for official use of FEM software for designing and simulation.

\section{REFERENCES}

1. Nickolas Kingsley, George E. Ponchak, and John Papapolymerou, " RF MEMS Sequentially Reconfigurable Sierpinski Antenna on a Flexible Organic Substrate With Novel DC-Biasing Technique", IEEE Transactions on Antennas and Propagation, Vol. 56, No. 1, pp.108-118, January 2008.

2. Y. Tawk, J. Costantine, K. Avery, and C. G. Christodoulou, "Implementation of a cognitive radio front-end using rotatable controlled reconfigurable antennas," IEEE Trans. Antennas Propag, vol. 59, no. 5, pp. 1773-1778, May 2011.

3. J. R. Kelly, P. Song, P. S. Hall, and A. L. Borja, "Reconfigurable 460 $\mathrm{MHz}$ to $12 \mathrm{GHz}$ antenna with integrated narrowband slot," Progress in Electromagn. Res. C, vol. 24, pp. 137-145, 2011.

4. G. T. Wu, R. L. Li, S. Y. Eom, S. S. Myoung, K. Lim, J. Laskar, S. I. Jeon, and M. M. Tentzeris, "Switchable quad-band antennas for cognitive radio base station applications," IEEE Trans. Antennas Propag., vol. 58, no. 5, pp. 14668-1476, May 2010.

5. E. Ebrahimi, J. R. Kelly, and P. S. Hall, "Integrated wide-narrowband antenna for multi-standard radio," IEEE Trans. Antennas Propag., vol. 59, no. 7, pp. 2628-2635, Jul. 2011.

6. J.Guterman, A.Moreira, C. Peixeiro, andY. Rahmat-Samii, "Wrappedmicrostrip antennas for laptop computers," IEEE Antennas Propag. Mag., vol. 51, no. 4, pp. 12-39, Aug. 2009.

7. J. Robinson and Y. Rahmat-Samii, "Particle swarm optimization in electromagnetics," IEEE Trans. Antennas Propag., vol. 52, no. 2, pp.397-407, Feb. 2004.

8. F. Yang, X.-X. Zhang, X. Ye, and Y. Rahmat-Samii, "Wide-band Eshaped patch antennas for wireless communications," IEEE Trans.Antennas Propag., vol. 49, no. 7, pp. 1094-1100, Jul. 2001.

9. N. Jin and Y. Rahmat-Samii, "Parallel particle swarm optimization and finite-difference time-domain (PSO/FDTD) algorithm for multiband and wide-band patch antenna designs," IEEE Trans. Antennas Propag., vol. 53, no. 11, pp. 3459-3468, Nov. 2005.

10. H. Rajagopalan, J. M. Kovitz, and Y. Rahmat-Samii, "Frequency reconfigurable wideband E-shaped patch antenna: Design, optimization, and measurements," in Proc. IEEE Antennas Propag. Soc. Int. Symp. (APSURSI), Jul. 8-14, 2012, pp. 1-2.

11. Y. Rahmat-Samii, J. M. Kovitz, and H. Rajagopalan, "Nature-inspired optimization techniques in communication antenna designs," Proc. IEEE, vol. 100, no. 7, pp. 2132-2144, Jul. 2012.

12. G. M. Rebeiz, RF MEMS: Theory, Design and Technology. New York, NY, USA: Wiley, 2003.

13. Harish Rajagopalan, Joshua M. Kovitz, and Yahya Rahmat-Samii, ” MEMS Reconfigurable Optimized E-Shaped Patch Antenna Design for Cognitive Radio", IEEE transactions on antennas and propagation, Vol. 62, NO. 3, pp.1056-1064, March 2014.

14. Tony J. Jung, Ik-Jae Hyeon, Chang-Wook Baek, and Sungjoon Lim, ” Circular/Linear Polarization Reconfigurable Antenna on Simplified RF-MEMS Packaging Platform in K-Band", IEEE transactions on antennas and propagation, Vol. 60, No. 11, pp.5039-5045, November 2012.

15. Caner Guclu, Julien Perruisseau-Carrier, and Ozlem Aydin Civi," Proof of Concept of a Dual-Band CircularlyPolarized RF MEMS Beam-Switching Reflectarray", IEEE transactions on antennas and propagation, Vol. 60, No. 11, pp.5451-5455, November 2012.

16. Chih-Chieh Cheng, Balaji Lakshminarayanan, and Abbas AbbaspourTamijani, " A Programmable Lens-Array Antenna With Monolithically Integrated MEMS Switches", IEEE transactions on microwave theory and techniques, Vol. 57, No. 8, pp.1874-1884, August 2009. 